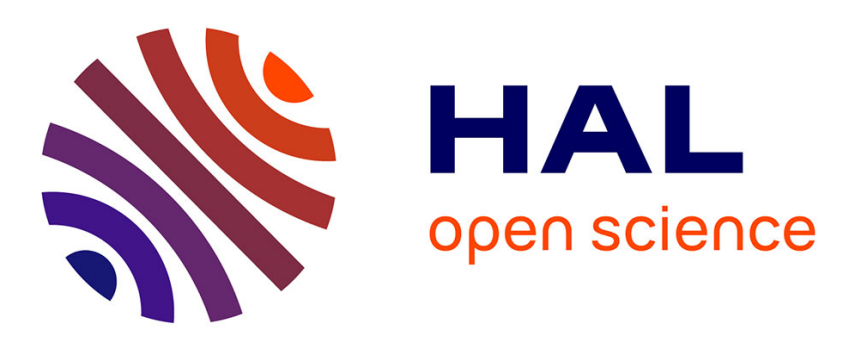

\title{
Grain and phase stress criteria for behaviour and cleavage in duplex and bainitic steels
}

Karim Inal, Raphaël Pesci, Jean-Lou Lebrun, Olivier Diard, Renaud Masson

\section{To cite this version:}

Karim Inal, Raphaël Pesci, Jean-Lou Lebrun, Olivier Diard, Renaud Masson. Grain and phase stress criteria for behaviour and cleavage in duplex and bainitic steels. Fatigue and Fracture of Engineering Materials and Structures, 2006, 29 (9-10), pp.685-696. 10.1111/j.1460-2695.2006.01056.x . hal-01203493

\section{HAL Id: hal-01203493 \\ https://hal.science/hal-01203493}

Submitted on 23 Sep 2015

HAL is a multi-disciplinary open access archive for the deposit and dissemination of scientific research documents, whether they are published or not. The documents may come from teaching and research institutions in France or abroad, or from public or private research centers.
L'archive ouverte pluridisciplinaire HAL, est destinée au dépôt et à la diffusion de documents scientifiques de niveau recherche, publiés ou non, émanant des établissements d'enseignement et de recherche français ou étrangers, des laboratoires publics ou privés. 


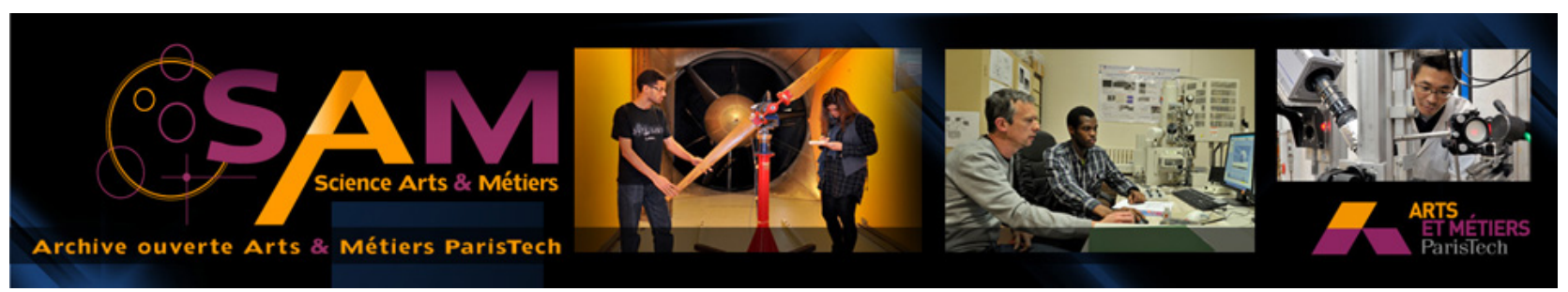

\section{Science Arts \& Métiers (SAM)}

is an open access repository that collects the work of Arts et Métiers ParisTech researchers and makes it freely available over the web where possible.

This is an author-deposited version published in: http://sam.ensam.eu

Handle ID: .http://hdl.handle.net/10985/10129

\section{To cite this version :}

Karim INAL, Raphaël PESCI, Jean-Lou LEBRUN, Olivier DIARD, Renaud MASSON - Grain and phase stress criteria for behaviour and cleavage in duplex and bainitic steels - Fatigue \& Fracture of Engineering Materials \& Structures - Vol. 29, n9-10, p.685-696 - 2006 


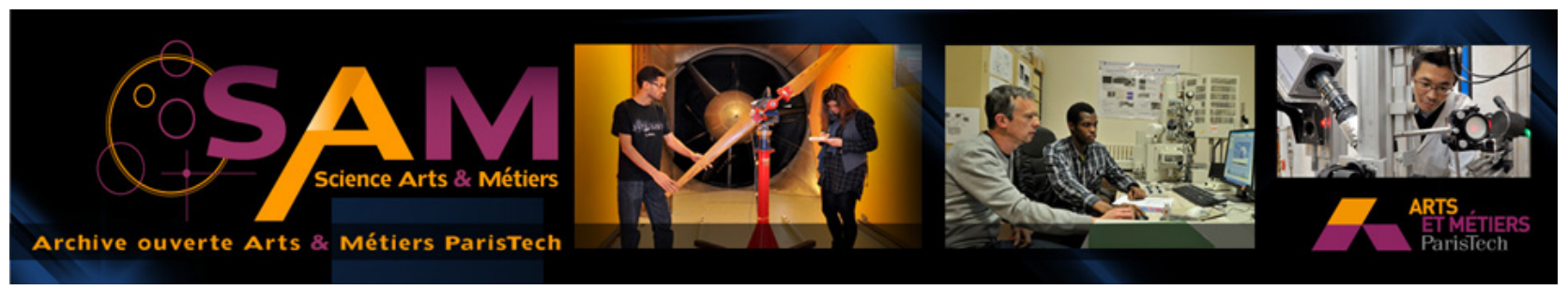

Science Arts \& Métiers (SAM)

is an open access repository that collects the work of Arts et Métiers ParisTech researchers and makes it freely available over the web where possible.

This is an author-deposited version published in: http://sam.ensam.eu Handle ID: .http://hdl.handle.net/null

\section{To cite this version :}

Karim INAL, Raphaël PESCI, Jean-Lou LEBRUN, Olivier DIARD, Renaud MASSON - Grain and phase stress criteria for behaviour and cleavage in duplex and bainitic steels - Fatigue \& Fracture of Engineering Materials \& Structures - Vol. 29, n9-10, p.685-696 - 2006 


\title{
Grain and phase stress criteria for behaviour and cleavage in duplex and bainitic steels
}

\author{
K. INAL ${ }^{1}$, R. PESCI ${ }^{2}$, J. L. LEBRUN ${ }^{3}$, O. DIARD ${ }^{4}$ and R. MASSON ${ }^{4}$ \\ ${ }^{1}$ MECASURF, ENSAM, 2 cours des Arts et Métiers, 13617 Aix en Provence cedex 1 - France, ${ }^{2}$ LPMM, ENSAM, 4 Av Augustin Fresnel, 57078 \\ Metz cedex 3 - France, ${ }^{3}$ LPMI, ENSAM, 2 Bd du Ronceray, BP 93525, 49035 Angers cedex 6 - France, ${ }^{4}$ MMC, EDF, Centre des Renardières, BP 1 , \\ 77250 Moret sur Loing - France
}

\begin{abstract}
A B S T R A C T Stress analyses by X-ray diffraction are performed on a cast duplex (32\% ferrite) stainless steel elbow and a bainitic (95\% ferrite) pressure vessel steel. During an in situ tensile test, micrographic observations are made (visible glides and microcracks) and related to the stress state determined in the individual ferritic grains (aged duplex) and the ferritic phase (bainite loaded at low temperatures). Several material parameters have been identified at different scales, as for example, the critical resolved shear stress of $245 \mathrm{MPa}$ for the aged ferritic grain (duplex) or $275 \mathrm{MPa}$ for bainite $\left(-60^{\circ} \mathrm{C}\right)$, a crystallographic cleavage propagation criterion of $465 \mathrm{MPa}$ (stress normal to $\{100\}$ planes), and a fracture stress of approximately $700 \mathrm{MPa}$ in the ferritic phase. Even though the two steels are different in many respects, the macroscopic fracture strains and stresses are well predicted by the polycrystalline model developed for bainite, whatever the temperatures tested (considering $7 \%$ of the grains reaching the local criterion).
\end{abstract}

Keywords behaviour; crystallographic criteria; damage; microstructure; phase interactions; stress analysis.

\section{INTRODUCTION}

The industrial processing of steels involves the use of various techniques (such as rolling, casting, welding, machining, etc.) that inevitably have an influence on the mechanical properties of materials. The characteristics of a given steel can then be said to depend on several forming parameters, on its chemical composition, on its phase morphology, etc. In the case of multiphase steels, it is therefore important to have a thorough knowledge of the production-related microstructure specificities of each phase and their effects on mechanical properties, with special attention to phase interactions. In fact, many studies have already characterized the industrial performances of steels, but in order to identify more precisely the mechanical properties and damage processes, the polycrystalline and heterogeneous nature of the material must be taken into account. Various scales in the material are, therefore defined and associated to a stress order description: ${ }^{1,2}$

1 First order corresponds to the macroscopic mechanical states;
2 Second order (or mesoscopic stress) is present on the crystalline level; the crystal orientation must be introduced to take the anisotropy of the properties into account, as expressed in the single crystal anisotropic Hooke's law, and

3 In the third order, the mechanical state varies over a few hundred interatomic distances. Its description is more complex since the local stresses depend on the dislocation densities, on their distribution, on their motion, etc.

In a multiphase material, another scale must be introduced, following Ref. [3]. It corresponds to the average stress over all crystals or grains of the considered phase: we will call it pseudo-macroscopic. In the present paper, superscripts I, II and III will denote, respectively, macroscopic (or pseudo-macroscopic), mesoscopic and microscopic mechanical states. To distinguish the macro or pseudo-macroscopic scales, subscripts $\alpha$ (ferrite), $\gamma$ (austenite) or $\mathrm{Fe}_{3} \mathrm{C}$ (cementite) will be added to the symbol. In the case of two-phase steels, Fig. 1 summarizes the different stress orders. To come to a better understanding of the contribution of each phase to the whole macroscopic behaviour, mechanical state determination on different scales must be considered as essential. 

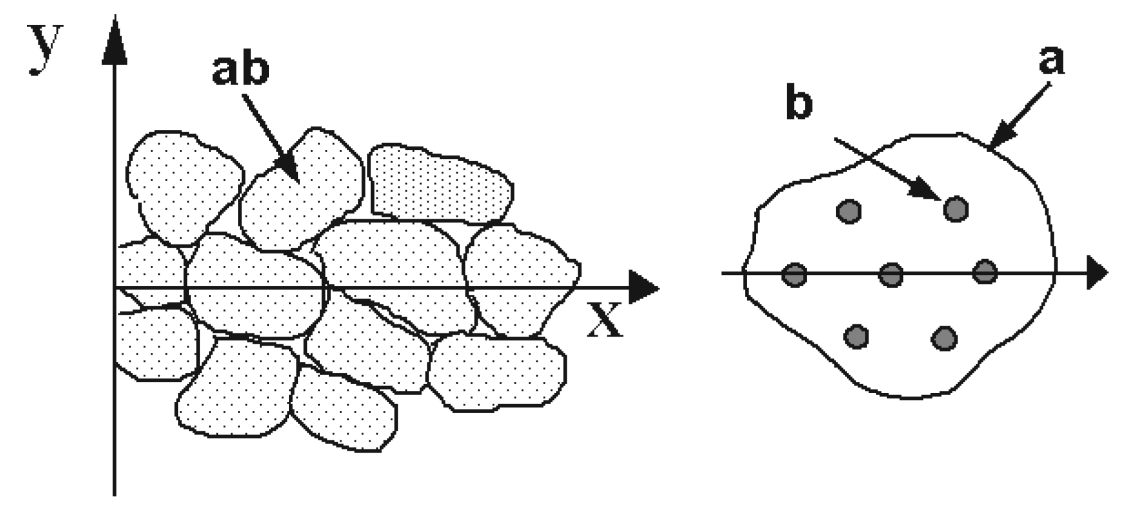
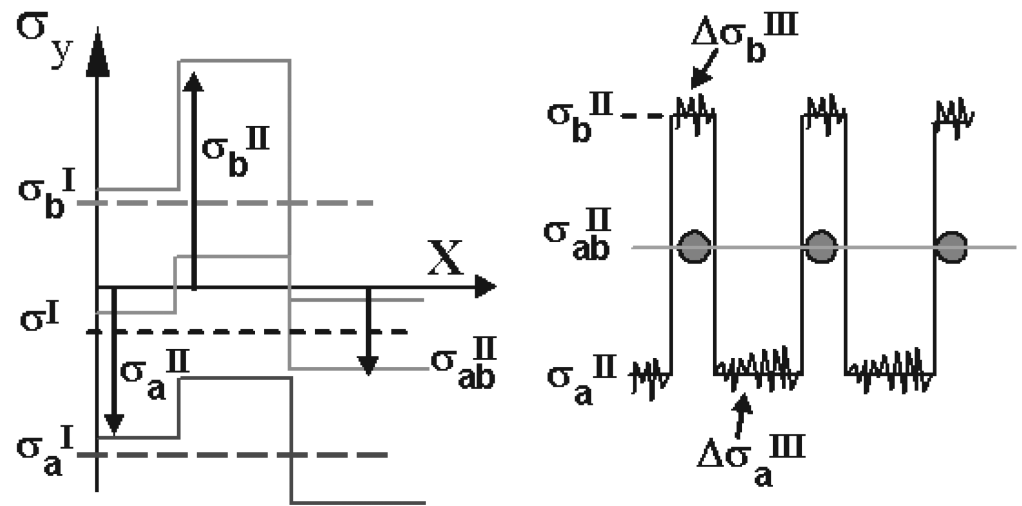

Fig. 1 Stress order distribution in a two-phase material along the $X$-axis. $\sigma^{\mathrm{I}}$ is the macroscopic stress; $\sigma^{\mathrm{I}}{ }_{\mathrm{i}}$ is the pseudo-macroscopic stress of each phase $i$, so that $\sigma^{\mathrm{I}}=\left\langle\sigma_{\mathrm{a}}^{\mathrm{I}}+\sigma_{\mathrm{b}}^{\mathrm{I}}\right\rangle$; the average of II order stresses is the order I stress: $\sigma^{\mathrm{I}}=\left\langle\sigma_{\mathrm{ab}}^{\mathrm{II}}\right\rangle, \sigma_{\mathrm{a}}^{\mathrm{I}}=\left\langle\sigma_{\mathrm{a}}^{\mathrm{II}}\right\rangle_{V_{\mathrm{a}}}, \sigma_{\mathrm{b}}^{\mathrm{I}}=\left\langle\sigma_{\mathrm{b}}^{\mathrm{II}}\right\rangle_{V_{\mathrm{b}}}$ and $\sigma_{\mathrm{ab}}^{\mathrm{II}}=\left\langle\sigma_{\mathrm{a}}^{\mathrm{II}}+\sigma_{\mathrm{b}}^{\mathrm{II}}\right\rangle_{V_{\text {Grain }}}$; in III order, $\Delta \sigma^{\mathrm{III}}{ }_{\mathrm{a}}$ and $\Delta \sigma^{\mathrm{III}}$ b vary over a few hundred interatomic distances.
Many studies concerning damage have been conducted on the macroscopic level (mainly tests on Charpy and CT specimens), but only a few of them consider the material as heterogeneous and multiphased. However, more local approaches have been recently instigated: ${ }^{4-9}$ they are very promising and should enable to relate various kinds of data on different scales to crack nucleation and propagation microscopic mechanisms and models. ${ }^{10-15}$

This work is a follow-up on the crystallographic approaches of behaviour and damage, intended to establish relevant criteria for the heterogeneous steels used by Electricite de France in pressurized water reactors. Since the integrity of important components, such as elbows and vessels, has to be warranted, the two steels constituting these two elements undergo a thorough study (Part 3):

1 A cast duplex material with coarse grains, whose premature thermal ageing causes a strong embrittlement of the ferritic phase (32\%);

2 A bainitic material with fine grains, composed of ferrite $(95 \%)$ and cementite.

In both steels, any applied plastic strain, homogeneous or not, will induce internal stresses on the phase and grain scale, since the two phases have a different behaviour (regarding yield stress and hardening). These stress states can be determined by X-Ray Diffraction (XRD), this technique being the only one permitting measurements in each phase $\mathrm{e}^{16-19}$ (Part 2). The aim is here to study the mechanical states and phase interactions on different scales, through the analysis of I and II stress orders. Deformation and damage mechanisms observations will be combined with stress determinations in order to establish stress criteria governing the plastic glide and the cleavage of the ferritic crystal and phase (Part 4).

These criteria will then be used to build a polycrystalline model of mechanical behaviour coupled with damage (Part 5). So far, crystalline plasticity on the grain scale is correctly modelled, but the coupling with a crystallographic approach of cleavage remains to be devised. With the homogenisation methods for the micro-macro transition, it is not possible to take into account third order stresses and strain heterogeneities. Therefore, the use of an average stress value for the whole grain (second order), smoothing all these third order perturbations, proves to be more judicious; it is both relevant and possible in this study, because some measurements are made directly on the average scale of the grain. In fact, this approach constitutes an advantage because the model parameters, which are directly identified on the grain scale in one steel, can be then extended to the same phase of the second steel.

\section{X-RAY DIFFRACTION}

The XRD technique is used for stress determination in crystalline materials. Like most stress analysis methods, 
Fig. 2 Measurement directions defined for $\mathrm{X}$-ray diffraction where $d_{\psi}$ corresponds to the interreticular distance for various $\psi$ angles.

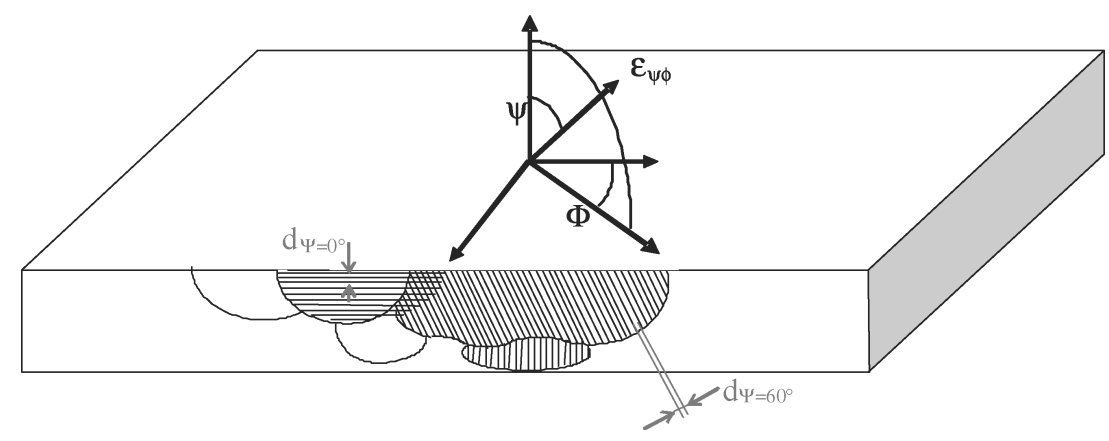

XRD does not allow to determine the stresses directly; they are calculated using a model relating strains and stresses. The basics for this tool have already been exposed and explained in many articles and manuals, therefore, we will only remind the reader of the fundamentals, as they are presented in depth in reference. ${ }^{6}$

The XRD method is based on the use of the lattice plane spacing $d_{\mathrm{hkl}}$ of a $\{b k l\}$ plane family as an internal strain gauge. To evaluate the stress tensor, it is necessary to measure the strain in several $\phi \psi$ directions (Fig. 2). The measured strain is linked through Bragg's law to the shift $\Delta 2 \theta_{\phi \psi}=2 \theta_{\phi \psi}-2 \theta_{0}$ of the corresponding diffraction peak:

$\varepsilon_{\phi \psi}=\frac{d_{\phi \psi}-d_{0}}{d_{0}}=\frac{\sin \theta_{0}}{\sin \theta_{\phi \psi}}-1 \approx-\frac{1}{2} \cdot \operatorname{cotan} \theta_{0} \cdot \Delta 2 \theta_{\phi \psi}$,

where $\varepsilon_{\phi \psi}$ is the strain in the direction of the normal to the $b k l$ planes, $d_{0}$ and $\theta_{0}$ are, respectively, the lattice spacing and the Bragg angle corresponding to a stress free state. Different methods have been proposed to calculate stress tensor from strain measurements. Two of these methods are presented in the following.

\section{Classical generalised method: $\sin _{\Psi}^{2}$ law}

It is the most used method and its practical implementation is the easiest. This method is based on the following equation, corresponding to the main relation for stress determination: ${ }^{20}$

$\varepsilon_{\phi \psi}=F_{\mathrm{ij}} \cdot \sigma_{\mathrm{ij}}^{\mathrm{I}}$.

The six independent $F$ components for a given direction $\phi_{\Psi}$ are called the X-ray Elastic Constants (XEC). Their values depend on the measurement direction, the observed lattice plane, the macroscopic and mesoscopic compliance tensors.

For an isotropic material, the XEC can be simplified, using two terms:

$F_{\mathrm{ij}}=\frac{1}{2} S_{2}\{b k l\} . n_{\mathrm{i}} . n_{\mathrm{j}}+S_{1}\{b k l\} . \delta_{\mathrm{ij}}$,

where $n=(\cos \phi \cdot \sin \psi, \sin \phi \cdot \sin \psi, \cos \psi)$ and the two terms $S_{1} b k l$ and $S_{2}\{b k l\}$ can be calculated from the macroscopic Poisson ratio, the Young modulus and the single crystal elastic constants. The development of $F$ leads to a simple relationship between $\sin _{\Psi}^{2}$ and the stress tensor components. This simple relation is the wellknown $\sin ^{2} \Psi$ equation:

$$
\begin{aligned}
\varepsilon_{\phi \psi}= & \frac{1}{2} S_{2}\{b k l\} \cdot\left(\sigma_{\phi}^{\mathrm{I}}-\sigma_{33}^{\mathrm{I}}\right) \cdot \sin ^{2} \psi+S_{1}\{b k l\} \cdot \operatorname{Tr}\left(\sigma^{\mathrm{I}}\right) \\
& +\frac{1}{2} S_{2}\{b k l\} \cdot \tau_{\phi}^{\mathrm{I}} \cdot \sin 2 \psi+\frac{1}{2} S_{2}\{b k l\} \cdot \sigma_{33}^{\mathrm{I}},
\end{aligned}
$$

with

$$
\begin{aligned}
& \sigma_{\phi}^{\mathrm{I}}=\sigma_{11}^{\mathrm{I}} \cdot \cos ^{2} \phi+\sigma_{12}^{\mathrm{I}} \cdot \sin 2 \phi+\sigma_{22}^{\mathrm{I}} \cdot \sin ^{2} \phi \\
& \text { and } \tau_{\phi}^{\mathrm{I}}=\sigma_{13}^{\mathrm{I}} \cdot \cos \cdot \phi+\sigma_{23}^{\mathrm{I}} \cdot \sin \phi .
\end{aligned}
$$

In many cases, the $\varepsilon_{\phi \psi}=f\left(\sin ^{2} \psi\right)$ graph is linear $\left(\sigma_{\phi}^{\mathrm{I}}\right.$ $\left.-\sigma_{33}^{\mathrm{I}}\right)$ is then proportional to the slope. If shearing $\tau$ exists, the line doubles itself and forms an ellipse, one branch of which corresponds to the positive $\psi$, the other to the negative $\psi$; shearing $\tau$ is then proportional to the 'opening' between the two branches (the negative average slope (major axis of the ellipse) expressing the compressive average stress state). For anisotropic materials, the $\varepsilon_{\phi \psi}=f\left(\sin ^{2} \psi\right)$ curve is no longer elliptic or linear, but undulating. ${ }^{21,22}$ This is due to two major causes: elastic and plastic anisotropy induced by crystallographic texture and/or pronounced plastic activity.

\section{Single crystal stress determination}

To sum up briefly, this method ${ }^{23-25}$ is based on the strain measurement of different $(b k l)$ planes, which is done in two steps. First, the orientation of one grain must be determined by pole figure analysis. The (HKL) [UVW] orientation of the grain provides the $\phi_{\Psi}$ position of any other $(b k l)$ plane and thus the strain measurements for at least $15(b k l)$ planes regularly scattered over the pole sphere can be taken. For a cubic crystal, the strain tensor is defined by the following equation in the reciprocal space system:

$\varepsilon_{\mathrm{ij}}=\left(\delta_{\mathrm{ij}}-a_{0}^{2} \cdot g^{i j}\right) / 2$,

where $\delta_{\mathrm{ij}}$ is the Kronecker symbol, $a_{0}$ the stress-free lattice parameter and $g^{i j}$ the contravariant metric tensor of the strained crystal that verifies $g^{i j} \cdot g_{\mathrm{ij}}=\delta_{\mathrm{ij}}$. It is calculated 
from the lattice planes spacing measured by diffraction:

$d_{\mathrm{hkl}}^{-2}=g^{i j} \cdot m_{\mathrm{i}} \cdot m_{\mathrm{j}}$,

(the $m_{\mathrm{i}}$ are the coordinates of the $(b k l)$ reciprocal vector, with $i=1$ to 3 ).

The components of the metric tensor are calculated by a multilinear regression analysis. The stress tensor components are then deduced from Hooke's law. The above calculations are in general carried out in the crystal reference frame. The stress tensor is then calculated in the sample reference frame. In this method, finding the stress-free reference state, which appears in the Eq. (6) as parameter $a_{0}$, turns out to be one of the difficulties.

In fact, for both methods, it is often assumed that $\sigma_{33}^{\mathrm{I}}$ is null; this allows the calculation of a stress free lattice parameter (for cubic structure). This assumption is justified by the fact that XRD only analyzes a very thin layer of material near the surface (a few micrometers), and it is reasonable to assume that no stress is applied on the free surface of the sample.

\section{STUDIED MATERIALS}

\section{Elaboration}

The first material is a cast duplex stainless steel (S1) composed of ferrite and austenite. It is quenched from 1050 to $1150{ }^{\circ} \mathrm{C}$ after a $6 \mathrm{~h}$ annealing: this treatment eliminates brittle phases and fixes the volume fraction of ferrite. The second material, elaborated by forging, is a low alloy steel 16MND5 similar to ASTM A508 cl. 3 (S2). It undergoes several heat treatments that lead to a microstructure com- posed of a ferritic matrix containing many cementite precipitates: two austenizations followed by water quench, a tempering and a stress-relief treatment. The chemical compositions of the two steels are given in Table 1; after the performed treatments, they lead to a ferrite volume fraction of, respectively, 32 and $95 \%$ for the S1 duplex steel and the S2 bainitic steel.

\section{Morphology}

The complete solidification of the $\mathrm{S} 1$ steel is characterized by primary ferritic grains, the order of the millimetre. Then, a major part of the ferrite transforms into austenite by solid-state germination and growth. Each grain (Fig. 3(a to f)) is composed of several austenite laths slightly disorientated from one another in a ferritic single crystal matrix; this morphology corresponds to a 'Widmanstäten' structure with a bipercolation of both austenite and ferrite (austenite and ferrite sub-grains overlapping one another).

The surface micrograph of the S2 steel (Fig. 3) shows former austenitic grains, the size of which varies from 40 to $80 \mu \mathrm{m}$. They have a complex tempered bainite microstructure composed of laths and packets with a ferrite/precipitates of cementite topology; these packets, which all have a different crystallographic orientation, define in fact the effective grain size of this material.

\section{Preliminary $\mathrm{X}$-ray analysis}

The pole figures realized in one grain (grain a of Fig. 3) of the $\mathrm{S} 1$ steel shows clearly that the grain is composed of two

Table 1 Chemical analysis (weight percentage, and balance iron) of the S1 duplex and S2 bainitic steels

\begin{tabular}{|c|c|c|c|c|c|c|c|c|c|c|}
\hline & $\mathrm{Cr}$ & $\mathrm{Ni}$ & $\mathrm{Si}$ & $\mathrm{Mn}$ & Mo & $\mathrm{Cu}$ & $\mathrm{P}$ & $\mathrm{S}$ & $\mathrm{C}$ & $\mathrm{N}$ \\
\hline S1 duplex & 21.9 & 10.15 & 1.19 & 1.07 & 2.71 & & & & 0.027 & 0.04 \\
\hline S2 bainite & 0.17 & 0.7 & 0.24 & 1.37 & 0.5 & 0.06 & 0.005 & 0.008 & 0.159 & 0.007 \\
\hline
\end{tabular}
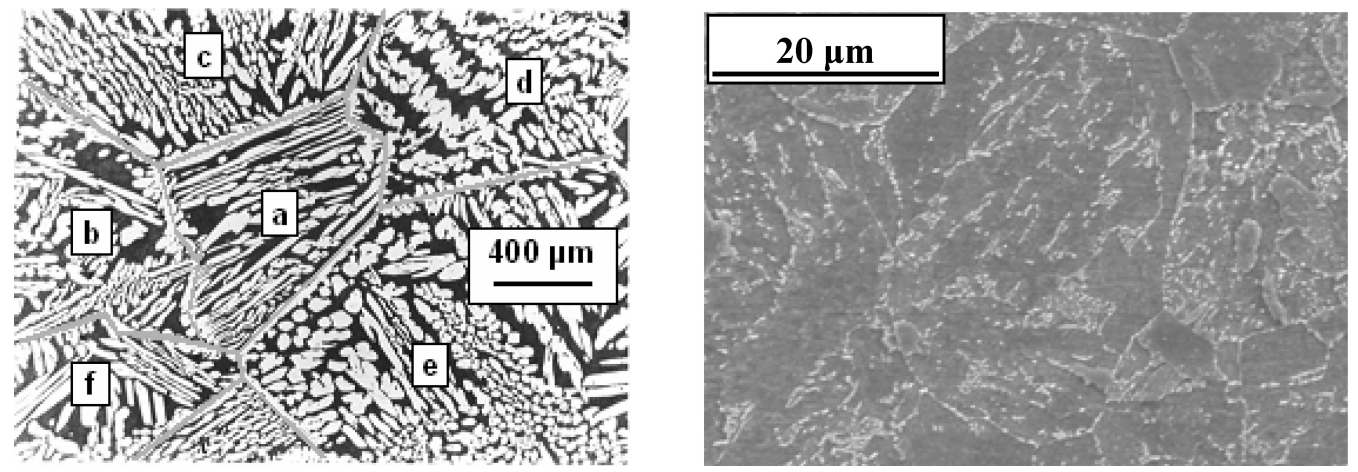

Fig. 3 Micrographs of the S1 steel (austenite corresponds to the bright areas ${ }^{6}$ ) and S2 one (former austenitic grains: dark ferrite areas with clear cementite precipitates). 


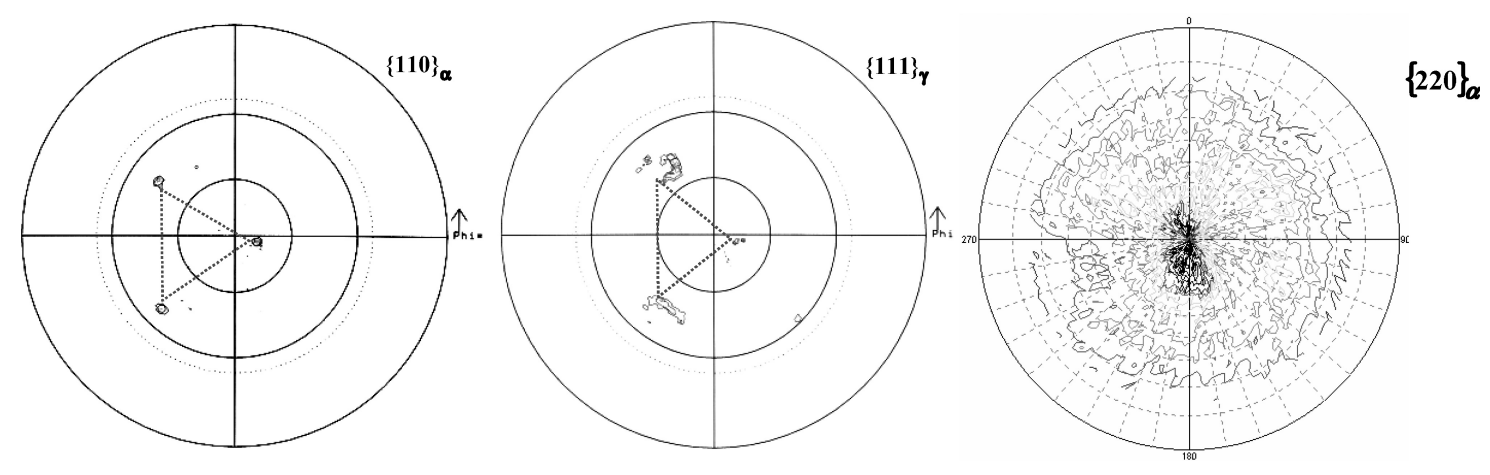

Fig. 4 Pole figures of each phase of the duplex S1 steel $\left(\{110\}\right.$ for the ferrite and $\{111\}$ for the austenite $\left.{ }^{6}\right)$ and $\{220\}$ pole figure of the ferritic phase of the S2 bainitic steel.

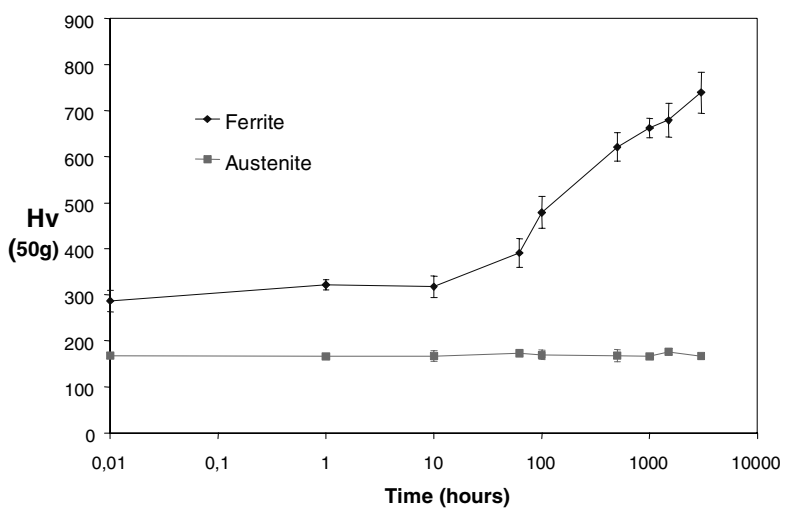

Fig. 5 Microhardness of each phase as a function of ageing (S1 duplex steel).

single crystals: one of ferrite, the other of austenite. Crystallographic orientation relations (Kurdjumov-Sachs type) between the two networks are also underlined in Fig. 4, where it can be seen that $\{111\}_{\gamma}$ and $\{110\}_{\alpha}$ poles of each phase are superimposed. Besides, the $\{220\}_{\alpha}$ ferrite pole figure of the $\mathrm{S} 2$ steel indicates no crystallographic texture.

\section{Mechanical properties}

For the S1 duplex steel, the microhardness (for austenite and ferrite) varies in function of the annealing treatment duration; results are plotted in Fig. 5. This annealing treatment leads to a ferrite embrittlement, with an increase in the microhardness from about $350 \mathrm{Hv}$ for the as-received material to $700-800 \mathrm{Hv}$ for the aged one, the hardness of austenite remaining constant around $200 \mathrm{Hv}$. It appears clearly that the behaviour of the treated material is brittle: ageing leads to a considerable loss of ductility, since the failure strain varies from approximately 30 to $2 \%$. In the following, aged specimens have been made from the ma-

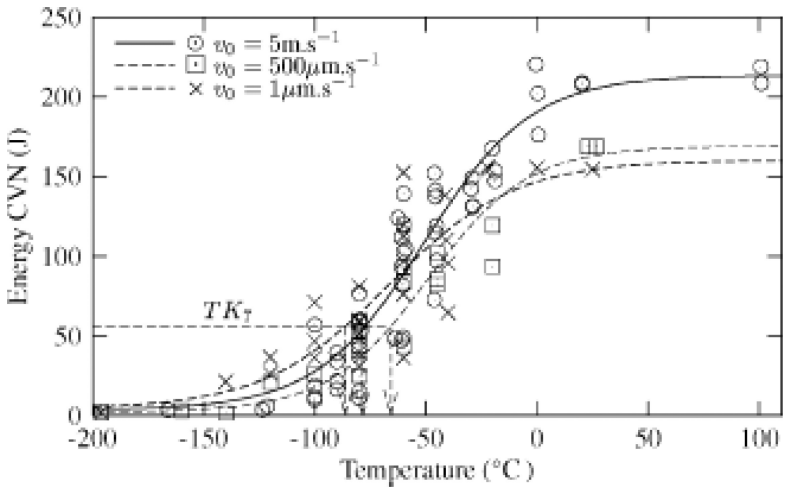

Fig. 6 Fracture toughness curve of the 16MND5 bainitic steel $\left[-196^{\circ} \mathrm{C} ; 100^{\circ} \mathrm{C}\right]$. Charpy experiments. ${ }^{26}$

terial treated at $400{ }^{\circ} \mathrm{C}$ during $3000 \mathrm{~h}$, this corresponding to natural ageing.

The fracture toughness curve for the S2 bainitic steel presented in Fig. 6 has been realized with Charpy experiments at different loading rates $b^{26}$, on a wide range of temperatures $\left[-196 ; 100^{\circ} \mathrm{C}\right]$ : it shows a large scattering of results in the ductile-to-brittle transition region, which varies from -100 to $60^{\circ} \mathrm{C}$. In order to emphasize cleavage, tensile tests have been performed at various low temperatures (until $-150^{\circ} \mathrm{C}$ ) in the present work.

\section{STRESSES BETWEEN PHASES AND GRAINS}

Two kinds of experiments are carried out: residual stress analyses after plastic strains and internal stress determinations during in situ bending and tensile tests (a fourpoint bending device and a tensile machine being set up on the diffractometre). Since the two steels have different microstructures, two XRD stress determination methods are used to analyze them:

1 It is possible to individualize by XRD each grain in the S1 duplex material. The single crystal method is then applied 
to the coarse structure; it only requires the elastic constants of the single crystals (see Table 2) to determine the elastic strain tensor, the stress tensor being deduced from Hooke's law.

2 The conventional method is used for the S2 bainitic steel because of its small grain size. The measurements are realized in the ferritic phase, using the XEC: $S_{1}=-1.28 \times$ $10^{-6} \mathrm{MPa}^{-1}$ and $1 / 2 S_{2}=5.92 \times 10^{-6} \mathrm{MPa}^{-1}$.

\section{S1 duplex steel}

Residual stresses are determined (see Fig. 7) in the austenitic and ferritic phases of six grains of a polycrystalline specimen preloaded on several stress levels, with respective uncertainties of 40 and $55 \mathrm{MPa}$. The residual axial stress (tensile direction) in each grain is, respectively, in tension for the ferritic crystal and in compression for the austenitic one, which confirms that the yield stress of the ferrite crystal is higher. To quantify the relative yield stress and the plastic anisotropy related to crystallographic orientation, the evolution of the stress state determined by XRD during an in situ tensile test (at each step of the loading) is followed in a few grains; the evolution of the stress tensor components for each phase is reported in Fig. 8 (the mean value of uncertainty is around $65 \mathrm{MPa}$ for ferrite and $70 \mathrm{MPa}$ for austenite). For the as-received and aged materials, Fig. 8 shows a strong heterogeneity of stress distribution between ferrite and austenite. This

Table 2 Elastic constants of each phase (single crystal) of the duplex steel

\begin{tabular}{lll}
\hline & Duplex steel & \\
\cline { 2 - 3 } & Ferrite & Austenite \\
\hline$C_{11}(\mathrm{GPa})$ & 237.4 & 197.5 \\
$C_{12}(\mathrm{GPa})$ & 134.7 & 124.5 \\
$C_{44}(\mathrm{GPa})$ & 116.4 & 122.0 \\
\hline
\end{tabular}

result is explained by the mechanical property differences between the two phases and especially the yield stress. In the case of the as-received material (Grain 6), this difference is about $200 \mathrm{MPa}$ (axial component) for $1.5 \%$ of the total strain (see Figs 8(b) \& (d)). Figures 8(a) and (c) as well as further measurements ${ }^{27}$ show that this difference gets more pronounced with ageing (250-500 MPa, depending on the crystallographic orientation, when the strain is about $1 \%$ ). The increase in yield stress due to ageing results in the axial stress in ferrite of the aged material being higher than that of the as-received one. For the level of strain reached, austenite saturates around a $300 \mathrm{MPa}$ stress, whereas ferrite can be loaded up to approximately $750 \mathrm{MPa}^{6}$ (shows that a grain can reach $965 \mathrm{MPa}$ ).

The stress values determined in the austenite phase of the as-received material and of the aged one do not seem to differ. This is to be expected since ageing does not affect the mechanical properties of austenite. The ferrite of both the aged material and the as-received one is in a uniaxial stress state, which corresponds to the applied loading path, while austenite can be in a biaxial stress state or present shear components. These results are in agreement with the fact that the material is composed of a hard phase and a soft phase. Given its stiffness, ferrite will follow the macroscopic loading while austenite will accommodate the total local strain more easily.

For a better understanding of the stress states induced by plastic strain, deformation and damage mechanisms are also observed during an in situ tensile. During the loading process, plastic activity first starts in the austenite subgrain (see the slip lines in the small islands of austenite in Fig. 9a), and is then transmitted to ferrite (sinuous slip lines). Considering the associated stress states, their projection on slip systems enables to identify a resolved critical shear stress of $\tau_{\mathrm{c}}^{\gamma}=95 \pm 15 \mathrm{MPa}$ for the austenite crystal, $\tau_{\mathrm{c}}{ }^{\alpha}=170 \pm 15 \mathrm{MPa}$ for the ferrite crystal in the as-received material and $\tau_{\mathrm{c}}{ }^{\alpha}=245 \pm 20 \mathrm{MPa}$ for the ferrite crystal in the aged one. ${ }^{28}$
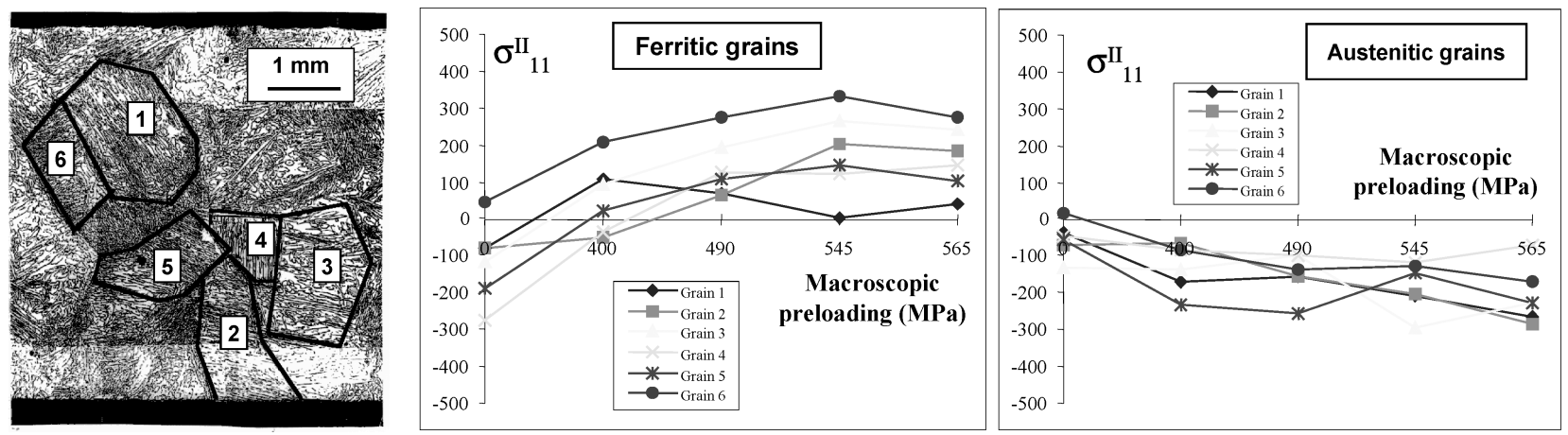

Fig. 7 Axial residual stresses in each phase of the six analyzed grains (with respective uncertainties of 40 and $55 \mathrm{MPa}$ for ferrite and austenite) as a function of a succession of macroscopic preloadings. 

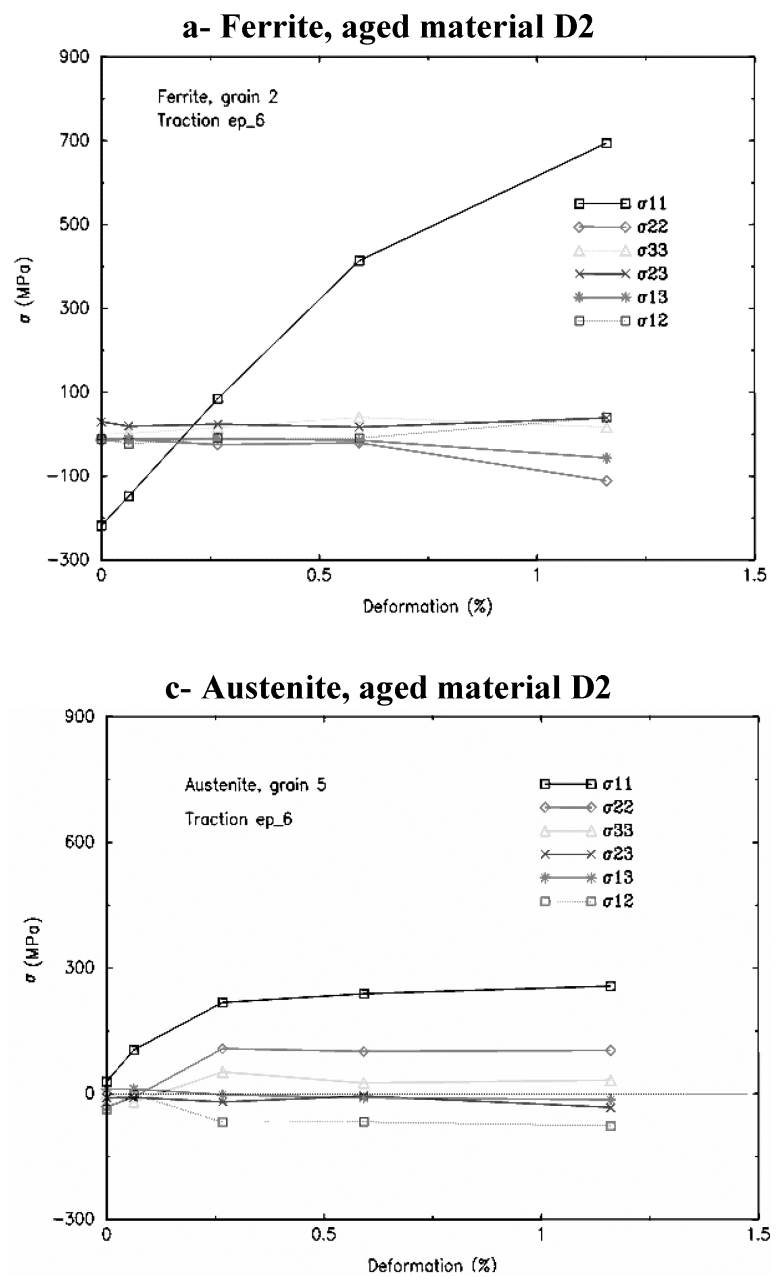

b- Ferrite, as-received material D2

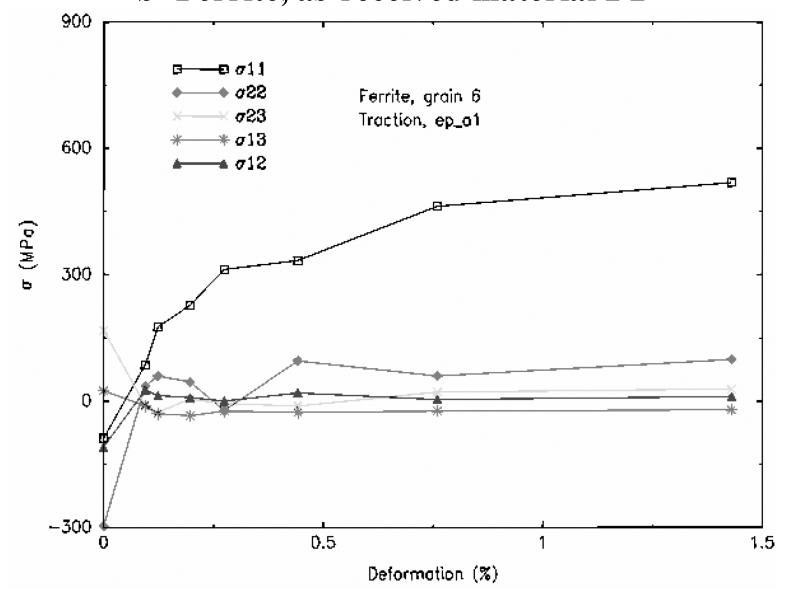

d- Austenite, as-received material D2

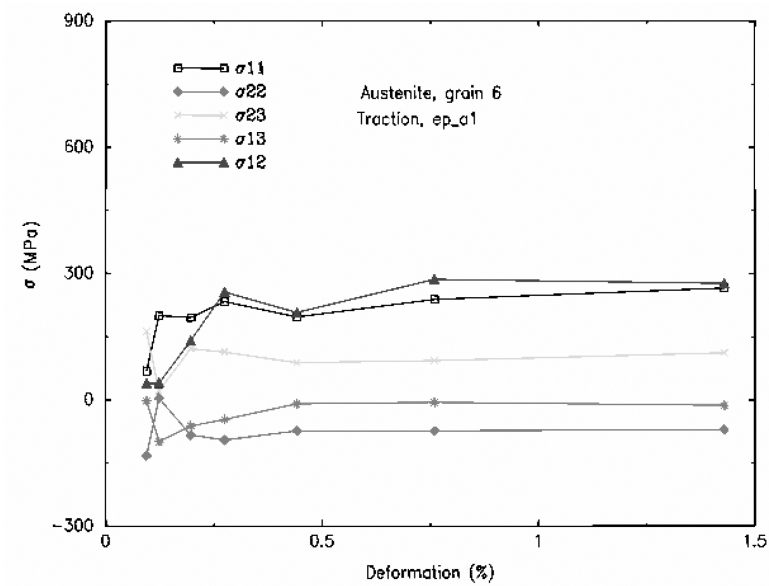

Fig. 8 Evolution of the stress tensor components during an in situ tensile test (the mean value of uncertainty is around $65 \mathrm{MPa}$ for ferrite and $70 \mathrm{MPa}$ for austenite).

(a)

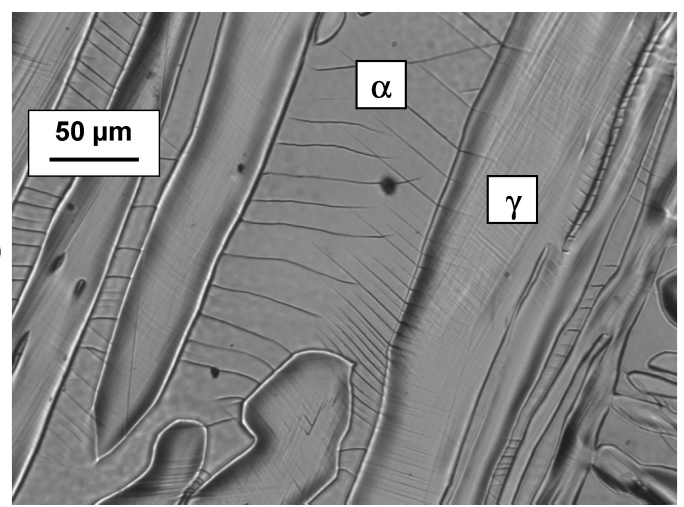

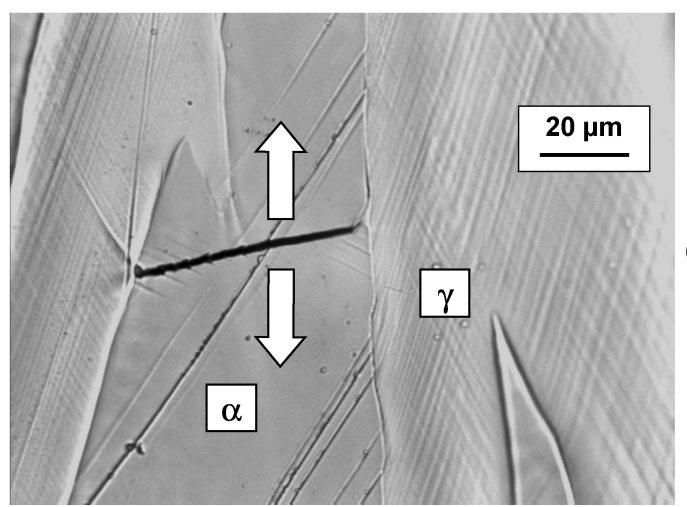

(b)

Fig. 9 Deformation (a) and damage (b) mechanisms identification during in situ tensile test.

The plastic flow is very quickly followed by damage, caused by the embrittlement of this steel. It can be observed in Fig. $9 \mathrm{~b}$ that cleavage occurs in ferrite by transgranular fracture (microcracks in the ferrite ligaments).
The macroscopic fracture is then induced by plastic instability in austenite. In order to promote damage in one particular grain and circumvent the difficulty due to the crystallographic orientation effect, the traditional tensile 
specimens studied by XRD are notched in order to introduce a stress concentration. ${ }^{6}$ A $10 \mathrm{~mm}$ notch radius is chosen so that no high applied stress triaxiality is introduced in the notched zone; the notched section generally contains one or two grains. Four samples are thus prepared and X-ray stress analyses are realized during in situ uniaxial tensile tests (until failure). As $\sigma^{\Pi 1} \alpha_{i j}$ is then experimentally determined in the ferrite of the various grains, it is especially interesting to follow the projection of this stress tensor on the normal to the $\{100\}$ planes, that are well known in literature to be cleavage planes for bodycentred cubic crystals: ${ }^{29}$

$\sigma^{\amalg I \alpha}\{100\}=n_{\mathrm{i}} \cdot \sigma_{\mathrm{ij}}^{\mathrm{II} \alpha} \cdot n_{\mathrm{j}}$

with $n$ the unit vector normal to $\{100\}$ planes.

A subscript c is added to the stress symbol when this stress is considered to be related to micrographic observations of cleavage initiation. A significant difference between the four crystals is noticed for the critical longitudinal stress values $\sigma_{c}{ }_{c}^{I I \alpha}{ }_{11}$ ( 1 being the tensile direction). The average value of this stress is $710 \mathrm{MPa}$ with a large standard deviation of $240 \mathrm{MPa}$. The $\sigma_{\mathrm{c}}{ }^{\mathrm{II} \alpha}{ }_{11}$ stress is absolutely not representative of local damage initiation; it is only an average value over a few grains. In the case of $\sigma_{c}{ }^{I I \alpha}{ }_{\{100\}}$ values, it can be observed that for the four studied samples, the results agree with an average value of $465 \mathrm{MPa}$, with a small dispersion (45 MPa). $\sigma_{\mathrm{c}}{ }^{\mathrm{II} \alpha}{ }_{\{100\}}$ is the critical cleavage stress and it can be considered as a local criterion. For these various tests, failure takes place for different macroscopic loadings, but on the crystal level, the critical value of the stress normal to $\{100\}$ cleavage planes remains the same: $465 \mathrm{MPa}$.

\section{S2 Bainitic steel}

Flat specimens are used to characterize the level and the sign of the residual stresses induced by a plastic strain (during tensile test). Axial (tensile direction) residual stresses are given in Table 3 for each phase of these specimens stretched at various strain levels (up to $15 \%$ ).

Contrary to S1 steel, the ferritic phase is here in compression (negative residual stresses), which is explained by its lower yield stress; this has been already observed in other materials such as pearlitic steels, with a difference between the macroscopic stress and the average stress in the ferritic phase of over $400 \mathrm{MPa} .{ }^{30}$ The volume frac-

Table 3 Residual stresses in each phase of the 16MND5 steel after macroscopic pre-strain at $-60{ }^{\circ} \mathrm{C}$

$\begin{array}{lll}\text { Overall pre-strain }(\%) & 6,5 & 11,9 \\ \text { XRD measurements in ferrite }(\mathrm{MPa}) & -80 \pm 20 & -105 \pm 30 \\ \text { Residual stresses in cementite }(\mathrm{MPa}) & 1520 & 1995\end{array}$

tion of cementite being too small, no measures (under laboratory conditions) are done in the S2 baintic steel; the stress in this phase is deduced using a classical mixture law, which shows that it is in high tension. This is comparable to the synchrotron measurements realized in cementite by ${ }^{30}$ Figure 10 shows the $\varepsilon_{\phi \Psi}=f\left(\sin ^{2} \psi\right)$ curve for the ferritic phase; it can be observed that the average negative slope of this curve is related to the compression average stress state (order I) of this phase. The deviations from the average slope are related to the anisotropic character of the local behaviour (order II); this anisotropy leads to different mechanical responses for each crystal orientation, which explains why this curve is a representation of the intergranular stresses.

Many sequenced and in situ tensile tests are realized at various low temperatures using a small tensile machine equipped with a temperature regulating system and set up right onto a diffractometre. Stress state distribution in each phase of the material is determined in relation to temperature, during loading and after unloading. At $-150^{\circ} \mathrm{C}$ for example, ferrite does not go beyond $670 \pm 30 \mathrm{MPa}$ (Fig. 11) while cementite reaches values the order of

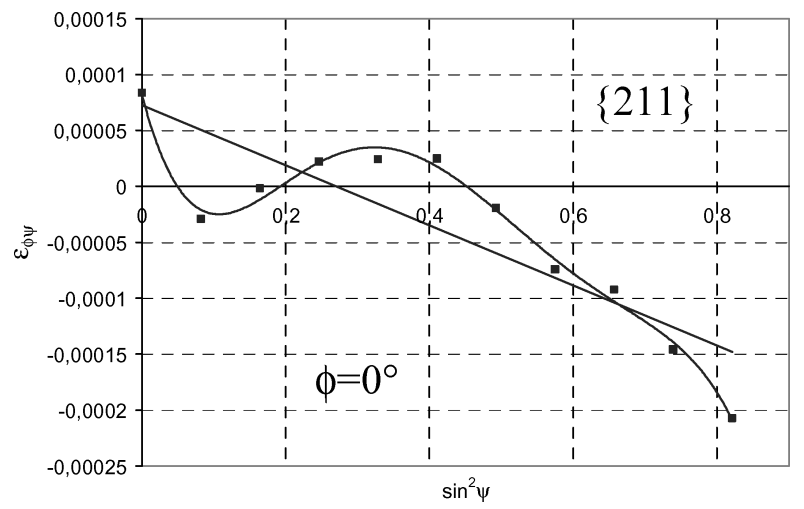

Fig. $10 \varepsilon_{\phi \psi}=f\left(\sin ^{2} \psi\right)$ intergranular strains in ferrite at $-60{ }^{\circ} \mathrm{C}$ $\left(\phi=0^{\circ}\right.$ : tensile direction, $8 \%$ macroscopic strain).

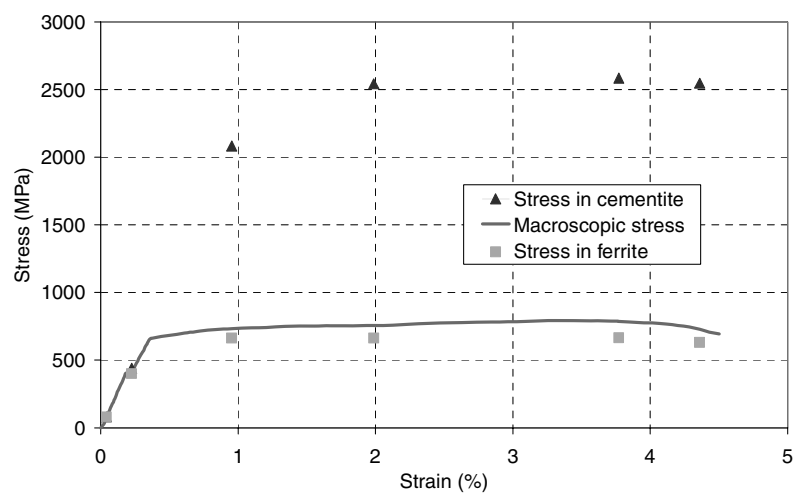

Fig. 11 Stress distribution in the 16MND5 bainitic steel during an in situ tensile test at $-150{ }^{\circ} \mathrm{C}$ (XRD measurements in ferrite and stress in cementite deduced from a mixture law). 
$2600 \mathrm{MPa}$ (mixture law). The stress in ferrite remains therefore lower than the macroscopic one, with a difference never exceeding $-150 \mathrm{MPa}$ (it is maximum at -196 $\left.{ }^{\circ} \mathrm{C}\right)$. This is very important when studying the failure of the material, because the fracture stress will not be considered in bainite, but in the ferritic phase. Indeed, the fracture stress in ferrite is close to $700 \mathrm{MPa}$ at $-150{ }^{\circ} \mathrm{C}$ and seems to remain constant with temperature (from 60 to $-150^{\circ} \mathrm{C}$ ). This stress value agrees with the average stress of $710 \mathrm{MPa}$ in ferritic grains which has been determined in the S1 duplex steel. A $\sigma_{\mathrm{c}}^{\mathrm{I} \alpha}$ of about $700 \mathrm{MPa}$ can be therefore considered as an average stress criterion for damage of the ferritic phase.

\section{BEHAVIOUR AND DAMAGE POLYCRISTALLINE MODELLING}

For the bainitic steel, a polycrystalline modelling with a two-level homogenization has been developed ${ }^{7}$ to take into account each kind of heterogeneity as well as the phase and grain interactions; a Mori-Tanaka formulation $^{31}$ enables to describe the elastoplastic behaviour of a bainitic single crystal (cementite inclusions in a ferritic matrix), while the transition to polycrystal is achieved by a self-consistent approach. ${ }^{32}$ In addition, cementite inclusions are considered to be exclusively elastic while the plastic strain of ferrite is induced by crystallographic gliding when slip systems become active.

The constitutive relation of a bainitic single crystal must be first presented. The activation of slip systems is determined thanks to an energetic criterion and a two-phase elastoplastic tangent modulus $l_{\alpha / F e_{3} C}$ characterizes the local behaviour law: ${ }^{33}$

$$
\begin{aligned}
\dot{\sigma}^{t}=l_{\alpha / \mathrm{Fe}_{3} \mathrm{C}} \cdot \dot{\varepsilon}^{t}= & {\left[l_{\alpha}+f \cdot\left(C_{\mathrm{Fe}_{3} \mathrm{C}} \cdot T-l_{\alpha}\right)\right] } \\
\cdot & {[(1-f) \cdot I+f \cdot T]^{-1} \cdot \dot{\varepsilon}^{t}, }
\end{aligned}
$$

where $\dot{\sigma}^{t}$ and $\dot{\varepsilon}^{t}$ are, respectively, the overall stress and strain rates of the bainitic grain, $f$ is the volume fraction of cementite, $C_{\mathrm{Fe}_{3} \mathrm{C}}$ and $l_{\alpha}$ are the elastic and elastoplastic characteristics of each phase and $T=[I+$ $\left.S^{\text {Esh }} \cdot l_{\alpha}^{-1} \cdot\left(C_{\mathrm{Fe}_{3} \mathrm{C}}-l_{\alpha}\right)\right]^{-1}$ comes from the solution of the elastic inclusion problem, with $S^{\text {Esh }}$ the Eshelby tensor. ${ }^{34}$

The polycrystal is then considered to be an aggregate of bainitic single crystals, so that a self-consistent approach can be adopted. The macroscopic constitutive relation therefore reads:

$$
\begin{aligned}
& \sum=L_{\alpha / \mathrm{Fe}_{3} \mathrm{C}} \cdot \dot{E}^{t} \quad \text { with } L_{\alpha / \mathrm{Fe}_{3} \mathrm{C}} \\
& =\overline{l_{\alpha / \mathrm{Fe}_{3} \mathrm{C}} \cdot\left[I+S^{\mathrm{Esh}} \cdot L_{\alpha / \mathrm{Fe}_{3} \mathrm{C}}^{-1} \cdot\left(l_{\alpha / \mathrm{Fe}_{3} \mathrm{C}}-L_{\alpha / \mathrm{Fe}_{3} \mathrm{C}}\right)\right]^{-1}}
\end{aligned}
$$

where $\dot{E}^{t}$ and $\dot{\Sigma}$ are, respectively, the macroscopic strain

\begin{tabular}{|c|c|c|c|c|c|}
\hline \multicolumn{3}{|c|}{ Elastic constants $(\mathrm{MPa})$} & \multirow{2}{*}{$\begin{array}{l}\text { Critical } \\
\text { shear } \\
\text { stress }(\mathrm{MPa}) \\
\tau_{c}^{g}\end{array}$} & \multicolumn{2}{|c|}{$\begin{array}{l}\text { Hardening } \\
\text { parameters } \\
(\mathrm{MPa})\end{array}$} \\
\hline $\mathrm{C}_{11}$ & $\mathrm{C}_{12}$ & $\mathrm{C}_{44}$ & & $b_{1}$ & $b_{2}=1,2 \cdot b_{1}$ \\
\hline 237400 & 134700 & 116400 & 275 & 225 & 270 \\
\hline
\end{tabular}
and stress rates and $L_{\alpha / \mathrm{Fe}_{3} \mathrm{C}}$ is the average macroscopic
Table 4 Elastic constants and parameters of the model identified with a tensile test at $-60{ }^{\circ} \mathrm{C}$

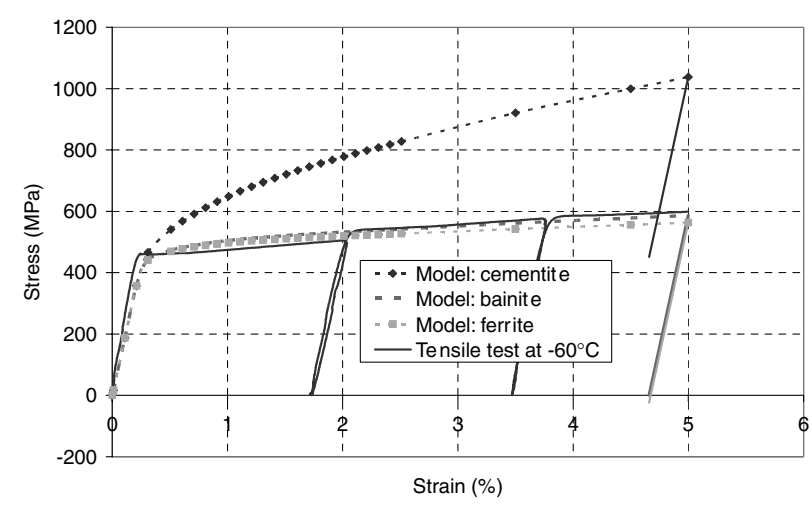

Fig. 12 Overall stress-strain curve during a tensile test at $-60^{\circ} \mathrm{C}$ on the 16MND5 steel: experimental results are compared to simulated ones. Average stresses in cementite and ferrite are also reported on this figure.

elastoplastic modulus, with $l_{\alpha / \mathrm{Fe}_{3} \mathrm{C}}$ the elastoplastic moduli of the different bainitic single crystals.

Several simulations of the polycrystal behaviour have been thus realized to determine the stress distribution during tensile tests. When considering a thousand grains (the crystallographic orientations of which are chosen at random), plastic gliding on $\{110\}\langle 111\rangle$ and $\{211\}\langle 111\rangle$ slip systems in ferrite, as well as the same elastic constants for each phase ${ }^{35}$ and the parameters identified through experiments (critical shear stress, self-hardening and latent hardening: see Table 4), the stress states can be predicted at $-60{ }^{\circ} \mathrm{C}$; they are presented in Fig. 12. The stress is higher in cementite, while the stress in ferrite remains close to that in bainite $\left(\sigma_{\mathrm{Fe}_{3} \mathrm{C}}>\sigma_{\alpha / \mathrm{Fe}_{3} \mathrm{C}}>\sigma_{\alpha}\right)$, whatever the temperature considered. One can also notice that the cementite seems to saturate above a certain strain; it almost stops gathering strain, which is then accommodated by ferrite. This can be explained by the fact that Fig. 12 represents the stress in each phase as a function of the applied macroscopic strain; when considering the evolution of stress in cementite in relation to strain in cementite (and not to the macroscopic strain anymore), Fig. 13 confirms that the behaviour of this phase is exclusively elastic. So in fact, there is a stress and strain distribution in each phase of the $16 \mathrm{MND} 5$ steel (ferrite and cementite). These numerical results are consistent with the experimentally observed 


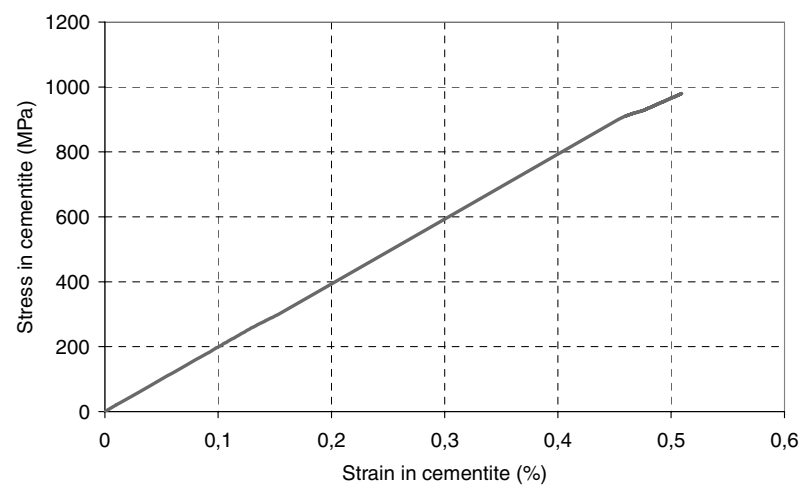

Fig. 13 Average stress in cementite $\left(\sigma_{11}\right.$ component) as a function of the average strain in cementite $\left(\varepsilon_{11}\right.$ component) during a tensile test at $-60{ }^{\circ} \mathrm{C}(4.5 \%$ macroscopic strain).

one, even if the difference between bainite and ferrite is a little underestimated.

The $\varepsilon_{\phi \psi}=f\left(\sin ^{2} \psi\right)$ intergranular strain can also be calculated with the proposed modelling, by projecting the elastic strain tensor normally to the considered diffracting plane:

$\varepsilon_{\phi \psi}=\left\langle n_{\mathrm{i}} \cdot \varepsilon_{\mathrm{ij}}^{e} \cdot n_{\mathrm{j}}\right\rangle_{\phi, \psi}$.

The model reproduces the same ripples as the ones experimentally observed (Fig. 14) and shows that intergranular strains and stresses are emphasized at low temperatures, due to the increase in yield stress; the grains undergo a stronger loading and the heterogeneities related to their orientation are enhanced. However, the calculated strain values slightly deviate from those measured by XRD, just like the average stress in each phase, still because the stress in ferrite is a little underestimated.

Finally, the model enables to determine the stress states in the material for any grain orientation. Since cleavage occurs normally to the $\{100\}$ planes in ferrite during ten- sile tests at low temperatures, it is able to predict in particular the evolution of the $\sigma^{\mathrm{II} \alpha}{ }_{\{100\}}$ stress in each bainitic single crystal, whatever be its orientation.

Thus, even though the ferrite of the S1 duplex steel is not exactly the same as that of the S2 bainitic steel, it becomes easy to introduce the cleavage criterion experimentally identified in the ferrite crystal: $\sigma_{c}{ }^{I I \alpha}{ }_{\{100\}}=$ $465 \mathrm{MPa}$. Some grains will attain it before others, depending on their crystallographic orientation; failure will be therefore supposed to take place when a sufficient number of them reach this value. Concerning duplex steel, several ferritic grains can cleave without actually inducing macroscopic fracture because the surrounding austenite in the bipercolated structure slows down the process by plastic accommodation. The macroscopic fracture takes place due to the plastic instability in austenite, the microcracks in ferrite propagating themselves along the austenitic slip lines. In fact, ${ }^{5}$ shows that even if a few grains cleave in a polycrystal, the material can remain mainly ductile, which results in the macroscopic yield stress being higher than the cleavage local stress. In the case of the 16MND5 steel, many in situ tensile tests have been realized in the scanning electron microscope at very low temperatures. At $-150^{\circ} \mathrm{C}$ in particular, it is possible to determine that the main crack initiates from a $\{100\}$ cleavage facet; furthermore, the breaking pattern is mostly ductile with the presence of several separate cleavage facets (6 or 7 grains having cleaved, as seen in Fig. 15).

The model requires that $7 \%$ of all the grains cleave (percentage constant with temperature) in order to obtain simulated fracture stress and strain during tensile tests at different temperatures in agreement with experimental ones; this fits with what is experimentally observed. It then shows that this failure criterion is reached sooner at low temperatures, which is explained by the increase in yield stress when temperature decreases (the yield stress is controlled by the critical shear stress: it is the only temperature
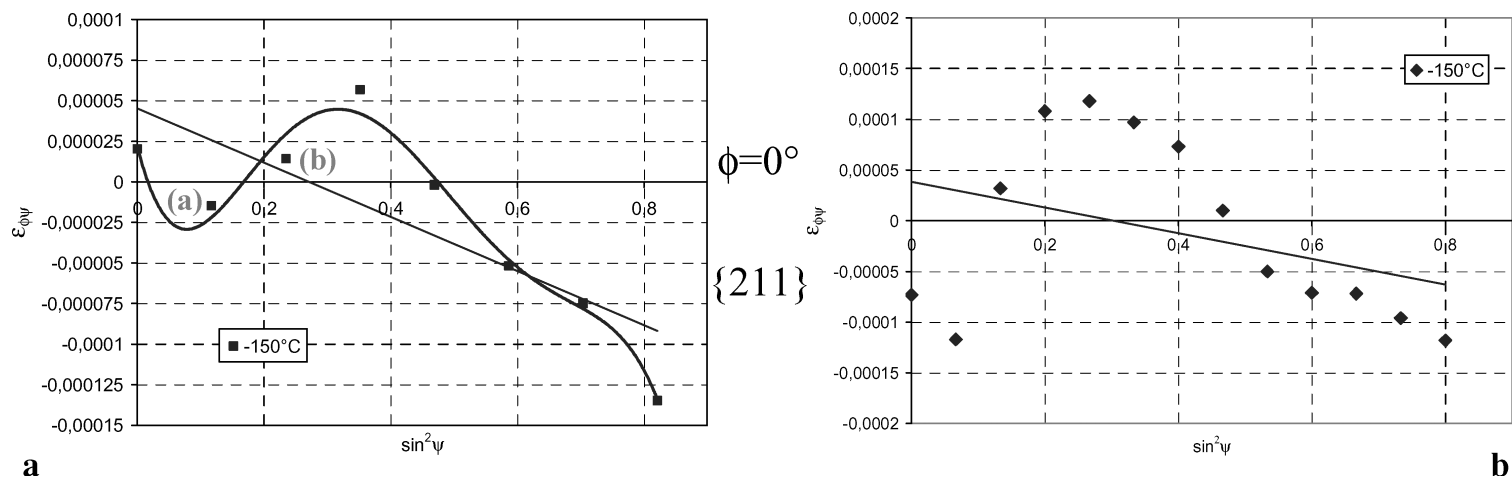

Fig. $14 \varepsilon_{\phi \psi}=f\left(\sin ^{2} \psi\right)$ intergranular strains at $-150{ }^{\circ} \mathrm{C}\left(\phi=0^{\circ}\right.$ : tensile direction, $4 \%$ macroscopic strain, after unloading). (a) XRD results. (b) Polycrystalline modelling. 


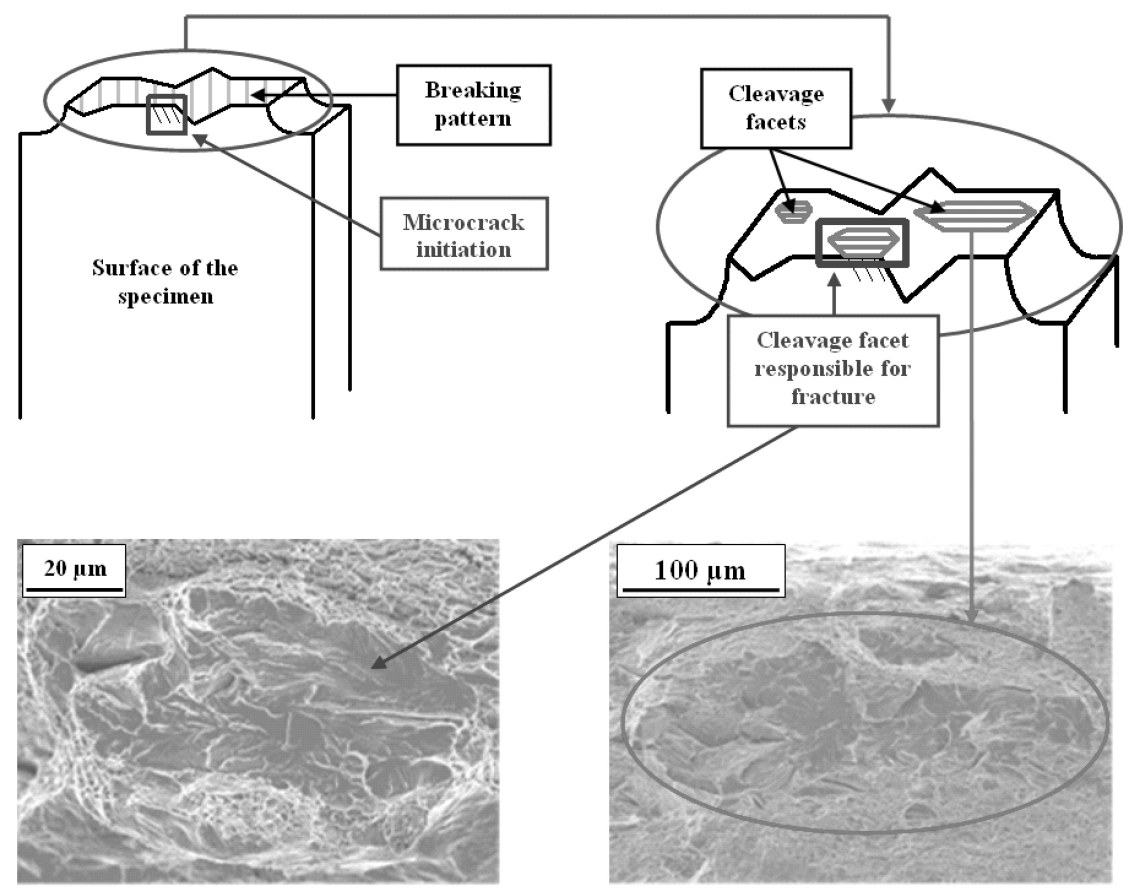

Fig. $15\{100\}$ cleavage facets on the breaking pattern of a flat specimen of $16 \mathrm{MND} 5$ steel broken at $-150{ }^{\circ} \mathrm{C}$.

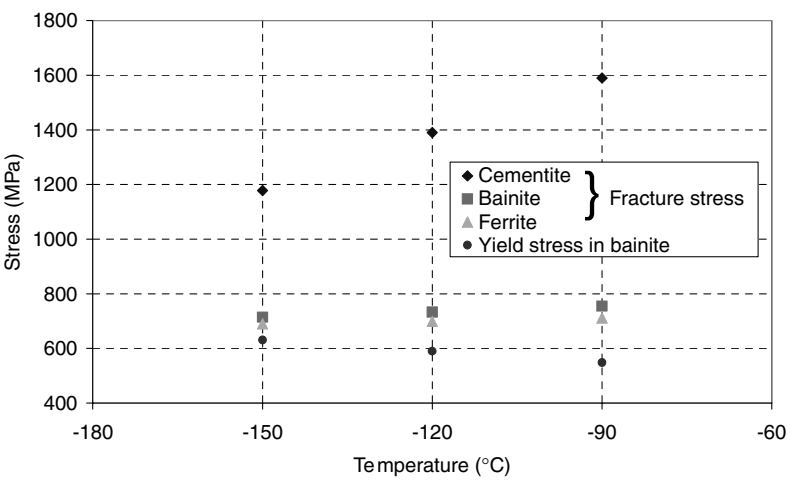

Fig. 16 Influence of temperature on the fracture stress in the 16MND5 steel.

dependent parameter, because all the tensile tests realized at different temperatures have shown that the slopes of the macroscopic stress-strain curves are similar in the elastic and the plastic parts (the hardening remaining constant)); the stress states and the stress difference between each phase are thus less important (Fig. 16). Besides, the fracture stress in ferrite remains constant with temperature, which is not the case in bainite and cementite; it strongly depends on the scale considered, its value being $465 \mathrm{MPa}$ on the scale of the crystal $\left(\sigma_{\mathrm{c}}{ }^{\mathrm{II} \alpha}{ }_{\{100\}}\right)$ and about $685 \mathrm{MPa}$ on the macroscopic one. This critical average stress $\left(\sigma_{\mathrm{c}}^{\mathrm{I} \alpha}\right)$ is not only consistent with the $700 \mathrm{MPa}$ determined by XRD in the ferrite of the S2 bainitic steel, but it is also close to the $710 \mathrm{MPa}$ determined in the ferrite of the S1 duplex steel.

\section{CONCLUSION}

Stress analyses by XRD have been successfully applied to duplex and bainitic steels. Since these materials have two completely different microstructures (grain size, phase morphology and crystallographic texture), two XRD methods have been adapted to their respective specificities.

First, the residual stress level and sign determined in each phase after plastic strain give valuable information about the mechanical behaviour of each phase in these steels: the yield stress of ferrite is higher than that of austenite in the duplex steel (both as-received and aged), but lower than the yield stress of cementite in the bainitic steel. The second experiment carried out deals with the internal stress evolution during an in situ loading. Concerning the duplex steel, the stress level points out that it is mainly the austenite crystal which accommodates most of the total strain applied to the grain, until cleavage of the ferrite crystal. For the 16MND5 steel, the stress state in the ferritic phase is lower than the macroscopic applied stress; furthermore, whereas the duplex steel requires a premature ageing treatment in order to promote cleavage in ferrite at room temperature, it is necessary to bring the bainitic steel down to low temperatures to induce cleavage. 
The stress states determined in the ferritic grain and in the ferritic phase are associated to the plastic flow and damage mechanisms observation. The coupling of the in situ XRD technique with microscopic observations, as well as the comparison with the polycrystalline modelling, make it possible to establish local and average criteria:

1 A critical resolved shear stress at room temperature $\tau_{\mathrm{c}}^{\gamma}=$ $95 \pm 15 \mathrm{MPa}$ for the austenite crystal and $\tau_{\mathrm{c}}{ }^{\alpha}=170 \pm$ $15 \mathrm{MPa}$ and $\tau_{\mathrm{c}}{ }^{\alpha}=245 \pm 20 \mathrm{MPa}$ for the ferrite one (asreceived and aged duplex). The latter value is comparable to the $\tau_{\mathrm{c}}{ }^{\alpha}=275 \mathrm{MPa}$ identified in the bainitic steel at $-60{ }^{\circ} \mathrm{C}$;

2 A crystallographic cleavage criterion in the ferritic crystal $\sigma_{c}{ }^{I I \alpha}{ }_{\{100\}}=465 \mathrm{MPa}$ and a fracture stress in the ferritic phase $\sigma_{\mathrm{c}}{ }^{\mathrm{I} \alpha}=700 \mathrm{MPa}$. It is also noticed that this last value is independent of the temperature.

However, this model could be further improved to derive average stress levels in the ferritic phase that would be quantitatively consistent with XRD measurements. The cleavage criterion in the ferrite crystal is also actually discussed. For example, when considering a critical stress of $565 \mathrm{MPa}$ instead of $465 \mathrm{MPa}$, the model rather requires that $2 \%$ of grains cleave to induce fracture (why not require only one single grain?). But in this case, the model, which correctly renders the behaviour of the 16MND5 steel as well as the stress distribution in each phase and intergranular stresses in ferrite, cannot predict the average fracture stresses and strains in relation to the temperature anymore. In fact, simulations display significant improvements in particular when considering the material as an aggregate of both ferritic and bainitic grains with a different volume fraction of cementite (this volume fraction remaining constant in the whole material) and a kinematic hardening (evolution with temperature). One can also imagine investigating a probabilistic approach (by applying random cementite volume fractions to different crystallographic orientations), considering other types of loadings (experiments and modelling) and using the finite elements method to take into account the intragranular heterogeneities. ${ }^{36}$

\section{Acknowledgements}

The authors would like to gratefully acknowledge G. Rousselier from EDF Research and Development Centre for his valuable contribution and advice.

\section{REFERENCES}

1 Greenough, G. B. (1949) Proceedings of the Royal Society of London A, 197 182-186.
2 Maeder, G. (1986) Chem Scripta. 26A 23-31.

3 Macherauch, E. Wohlfahrt, H. Wolfstieg, U. (1973) Härterei-Technische Mitteilungen. 28 201-211.

4 Bugat, S. (2000) Thesis, Ecole des Mines. Paris, France.

5 Argon, A. S. (2001) 7. Eng. Mater. Technol. 123 1-11.

6 M'Cirdi, L., Lebrun, J. L., Inal, K., Barbier, G. (2001) Acta Mater. 49 3879-3887.

7 Tanguy, B. (2001) Thesis, Ecole des Mines, Paris, France.

8 Nohava, J., Hauild, P., Karlík, M., Bompard, P. (2003) Mater. Charact. 49 211-217.

9 Pesci, R. (2004) Thesis, Ecole Nationale Supérieure d'Arts et Métiers. Metz, France.

10 Zener, C. (1948) ASM Seminar, Fracturing of Metals, American Society of Metals 3-31.

11 Stroh, A. N. (1954) Proceedings of the Royal Society of London A, 223 404-414.

12 Cottrell, A. H. (1958) Transaction of the Metallurgical Society of AIME 192-203.

13 Smith, E. (1968) Int. F. Fract. Mech. 4.

14 Griffith, A. A. (1920) Phil. Trans. Royal Soc. London A, 221 163-198.

15 Curry, D. A., Knott, J. F. (1978) Metal Science 511-514.

16 Hauk, V. Oudelhoven, R. V. M. Vaessen, G. J. H. (1982) Metall. Trans. A, 13A 1239-1244.

17 Noyan, I. C. Cohen, J. B. (1986) Mater. Sci. Eng., A, 79 149-.

18 Winholtz, R. A. Cohen, J. B. (1992) Metall. Trans. A. 23A 341-354.

19 Hadmar, P. Mabelly, P. Barrallier, L. et al. (1996) 7. Phys. IV , 6 219.

20 Hauk, V. (1997) Structural and Residual Stress Analysis by Nondestructive Methods, Elsevier.

21 Inal, K. Gergaud, P. François, M. et al. (1999) Scand. 7. Metall., 28 139-150.

22 Baczmanski, A. Wierzbanowski, K. Tarasiuk, J. (1995) Z. Metallkd., 86 507-511.

23 Crostack, H. A., Reimers, W. (1995) Residual Stresses in Science and Technology (Edited by Macherauh \& Hauk), x 289.

24 Gergaud, P., Dour, G., Inal, K. et al. (1996) Adv. X-ray Anal. 39.

25 Gergaud, P., Inal, K., Lebrun, J. L. (1996) Proceedings of the European Conference on Residual Stress, Cluny, France, 2, 1061.

26 Tanguy, B., Besson, J., Piques, R. et al. (2005) Eng. Fract. Mech., 72 49-72.

27 M'Cirdi, L., Inal, K., Lebrun, J. L. (2000) Adv. X-ray Anal. 397-406.

28 M'Cirdi, L. (2000) Thesis, Ecole Nationale Supérieure d'Arts et Métiers, Metz, France.

29 Lambert, A., Garat, X., Sturel, T., Gourgues, A. F., Gingell, A. (2000) Scripta Mater. 43 161-166.

30 Belassel, M. (1994) Thesis, Ecole Nationale Supérieure d'Arts et Métiers. Paris, France.

31 Mori, T., Tanaka, K. (1973) Acta Metall., 21 pp. 571-574.

32 Schmitt, C., Lipinski, P., Berveiller, M. (1997) Int. F. Plast., 13 183-199.

33 Benveniste, Y. (1987) Mech. Mater., 6 147-157.

34 Eshelby, J. D. (1957) Proceedings of the Royal Society of London A, 241 376-396.

35 Drapkin, B. M., Fokin, B. V. (1980) The Physics of Metals and Metallography, 49, 177-183.

36 Diard, O., Leclercq, S., Rousselier, G. et al. (2005) Int. F. Plast., 21 691-722. 